Tohoku J. Exp. Med., 2004, 204, 85-91

Case Report

\title{
Successful Allogeneic Bone Marrow Transplantation for Acute Myelogenous Leukemia after Drug-Induced Cardiomyopathy
}

\author{
Mitsuru Itoh, Kazuya Imai, ${ }^{1}$ Yasuko Kotone-Miyahara, ${ }^{1}$ Hiroko Yamada, ${ }^{1}$ \\ Hitoshi Ohno, ${ }^{1}$ Kokichi Yamamoto, ${ }^{1}$ Masaro Tashima, ${ }^{1}$ Moriaki Inoko, ${ }^{2}$ Ryuji \\ NOHARA $^{2}$ and TAKASHI UCHIYAMA ${ }^{1}$ \\ Department of Clinical Pathology and Laboratory Medicine, Kawasaki Medical \\ School, Kurashiki 701-0192, \\ ${ }^{1}$ Department of Hematology and Oncology, and ${ }^{2}$ Department of Cardiology, \\ Clinical Sciences for Pathological Organs, Graduate School of Medicine, Kyoto \\ University, Kyoto 606-8507
}

Itoh, M., Ifai, K., Kotone-Miyahara, Y., Yamada, H., Ohno, H., Yamamoto, K., Tashima, M., Inoko, M., Nohara, R. and Uchiyama, T. Successful Allogeneic Bone Marrow Transplantation for Acute Myelogenous Leukemia after Drug-Induced Cardiomyopathy. Tohoku J. Exp. Med., 2004, 204 (1), 85-91 — Anthracycline derivatives often induce cardiomyopathy. Patients with seriously decreased cardiac function due to chemotherapeutic drugs cannot usually receive allogeneic hematopoietic stem cell transplantation (SCT) for hematologic disorders. We successfully performed allogeneic bone marrow transplantation (BMT) in a patient with severe cardiomyopathy. An 18-year-old woman with relapsed acute myelogenous leukemia had cardiomyopathy due to previous anthracycline administration. She underwent allogeneic BMT from her HLA-identical brother. Her preconditioning regimen was cytosine arabinoside, etoposide, total body irradiation, and high-dose cyclophosphamide. Congestive heart failure (CHF) was not present before BMT. Right heart pressures were monitored by a pulmonary arterial balloon catheter system (SwanGanz catheter). After BMT, she had severe CHF, which was controlled using pimobendan and amrinone. Patients with cardiomyopathy can receive allogeneic SCT under strict hemodynamic management. — bone marrow transplantation; acute myelogenous leukemia; cardiomyopathy; congestive heart failure; hemodynamic management

(C) 2004 Tohoku University Medical Press

Received May 7, 2004; revision accepted for publication July 9, 2004.

Address for reprints: Mitsuru Itoh, M.D., Department of Clinical Pathology and Laboratory Medicine, Kawasaki Medical School, 577 Matsushima, Kurashiki 701-0192, Japan.

e-mail: itomitsu-kyt@umin.ac.jp 
Allogeneic (allo-) hematopoietic stem cell transplantation (SCT), including bone marrow transplantation (BMT), is performed routinely as a potentially curable treatment for malignant and non-malignant hematologic disorders. However, there is a group of patients who cannot receive allo-SCT because of severe cardiac, hepatic, or renal dysfunction, often as a result of prior chemotherapeutic drugs. Such patients are not suitable for SCT because of a high risk of mortality due to allo-SCT-related toxicity, especially since highdose cyclophosphamide (CY) is potentially cardiotoxic (Goldberg et al. 1986; Bearman et al. 1990; Braverman et al. 1991; Allen 1992; Ayash et al. 1992). Although a left ventricular ejection fraction (LVEF) of less than $50 \%$ has been generally considered a contraindication to SCT (Kakavas et al. 1995), there are no data on the absolute level of dysfunction which rules out alloSCT.

We successfully performed high-dose chemotherapy with total body irradiation (TBI), followed by allo-BMT, in a patient with very low LVEF under strict hemodynamic management. This case provides useful information about whether patients with cardiomyopathy can receive SCT.

\section{Case Report}

An 18-year-old Japanese woman was diagnosed with acute myelogenous leukemia (AML), M2 subtype by French-American-British classification (Bennett et al. 1976), in October 1994. Hematologic findings at diagnosis were white blood cell (WBC) $64.4 \times 10^{9} /$ liter with $25 \%$ neutrophils, $3 \%$ lymphocytes, $1 \%$ monocytes, $1 \%$ eosinophils, $7 \%$ metamyelocytes, and $63 \%$ blasts; platelets were $46 \times 10^{9} /$ liter and hemoglobin 5.2 $\mathrm{g} / 100 \mathrm{ml}$. Bone marrow was hypercellular with $75.2 \%$ blasts which contained Auer rods. Cytogenetic analysis revealed abnormal metaphases; 45, X, -X, t(8;21)(q22;q22). She had no cardiac dysfunction before induction therapy. She responded to induction therapy consisting of daunorubicin, enocitabine, 6-mercaptopurine, and prednisolone, but in May 1995 she relapsed following her fourth consolidation therapy. She again responded to re-induction therapy and received consolidation therapy three times. In October 1995, she was hospitalized to receive an allo-BMT from her 21-year-old, HLA-identical brother.

Her bone marrow was in complete remission with a karyotype of $46, \mathrm{XX}$, but her peripheral blood had some blasts. She also had a tumor on the right mastoid bone. Computed tomography (CT) and magnetic resonance imaging showed that it was myeloblastoma. Soon, she relapsed hematologically. The total dose of anthracycline received at this time was daunorubicin $1110 \mathrm{mg}$. Her LVEF was $44 \%$ by echocardiography and $32 \%$ by radionuclide gated blood pool imaging.

She received therapy consisting of pirarubicin, vindesine, cytosine arabinoside, 6-mercaptopurine, and prednisolone, and local irradiation (2 Gy $\times 15)$ to the mastoid region. The myeloblastoma disappeared, but her bone marrow was not in remission ( $16.8 \%$ blasts). LVEF decreased to $22 \%$ by echocardiography. Because of the sensitivity of her malignant cells to chemotherapeutic agents, we discussed the opinion of allo-SCT. She did not have any other organ dysfunction and no symptoms due to cardiac failure. We decide to perform an allo-BMT from her HLA-identical brother. Informed consent was obtained. In the institutional committee (held at Kyoto University Hospital), the validity of an allo-BMT was approved.

She had no complaints, but the heart rate was increased by light movement; walking, dressing, etc. For the purpose of controlling her heart rate, digoxin was administered. At first, we had intended to treat with a reduced conditioning regimen before transplantation. She was treated with cytosine arabinoside $200 \mathrm{mg}$ /day on days -14 to -10 , G-CSF $250 \mu \mathrm{g} /$ day on days -14 to -8 , etoposide $200 \mathrm{mg}$ on day -10 , and TBI 2 Gy $\times 6$ on days -8 to -5 . Hematologic findings on day -6 showed WBC $0.1 \times 10^{9} /$ liter with $3 \%$ blasts. For increasing therapeutic intensity, cyclophospha- 
mide $60 \mathrm{mg} / \mathrm{kg} /$ day on day -3 and $40 \mathrm{mg} / \mathrm{kg} /$ day on day -2 were administered under strict hemodynamic monitoring by a pulmonary arterial balloon catheter system (Swan-Ganz catheter) and using dobutamine and furosemide. Mesna was administered to prevent hemorrhagic cystitis, and hydration was $3000 \mathrm{ml} /$ day. After administering cyclophosphamide, the infusion volume was within $1000 \mathrm{ml} /$ day. Red blood cells (RBC) and plasma were removed (Braine et al. 1982) from the bone marrow transplant because reduction of the infused cell volume was critical to protect cardiac function. Swan-Ganz catheter management occurred on days -5 to +1 . Cyclosporine A (CsA) $(2.7 \mathrm{mg} / \mathrm{kg} /$ day, in two divided doses) and shortterm methotrexate $(10 \mathrm{mg}$ on day $+1,5 \mathrm{mg}$ on day +6) were administered as prophylaxis against graft-versus-host disease (GVHD). Heparin was administered as prophylaxis against veno-occlusive disease (VOD). Grade I cutaneous GVHD was observed. Hematologic engraftment (neutro- phils $>5 \times 10^{8} /$ liter) was on day +15 .

Administration of furosemide $(20 \mathrm{mg} /$ day $)$ was started again after bone marrow infusion because body weight and heart rate gradually increased. She complained of dyspnea and coughing on day +10 ; administration of dopamine, dobutamine, and $\mathrm{O}_{2}$ inhalation also were initiated, and symptoms promptly improved. Serum creatinine concentrations began to increase $(2.0 \mathrm{mg} / 100$ $\mathrm{ml}$ ) with a decrease in urinary volume due to adverse effects from CsA (serum concentrations at 155 to $219 \mathrm{ng} / \mathrm{ml}$ ). Dose reduction of CsA improved her renal function. However, on day +35 , Swan-Ganz catheter management was re-initiated because of lung congestion with dyspnea and cardiomegaly. Echocardiography showed that the LVEF was $20 \%$. Her Forrester classification (Forrester et al. 1977) fell to subset IV: pulmonary artery pressure (PAP) was $36 / 26 \mathrm{~mm} \mathrm{Hg}$, pulmonary capillary wedge pressure (PCWP) $26 \mathrm{~mm}$ $\mathrm{Hg}$, right atrial pressure (RAP) $14 \mathrm{mmHg}$, and

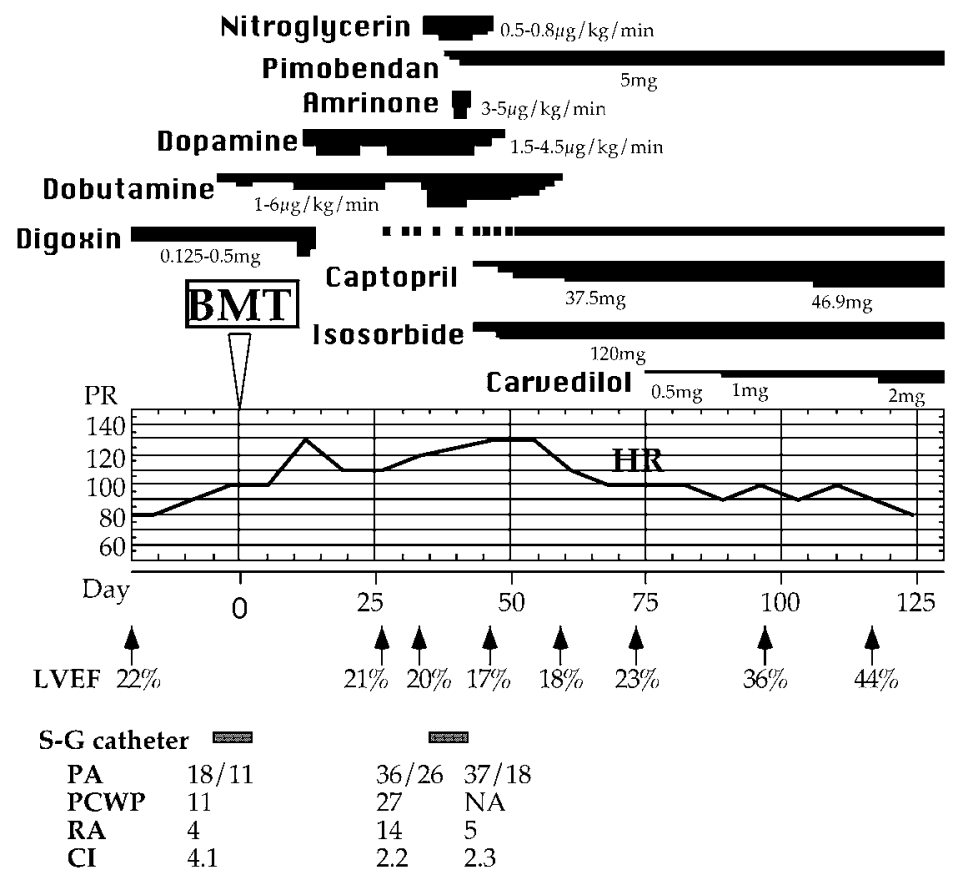

Fig. 1. Clinical course of patient. This figure shows cardiological management, especially medication and changes of cardiac parameters.

HR, heart rate (/min.); LVEF, left ventricular ejection fraction; S-G, Swan-Ganz; PAP, pulmonary artery pressure $(\mathrm{mmHg})$; PCWP, pulmonary capillary wedge pressure (mmHg); RAP, right atrial pressure $(\mathrm{mmHg})$; CI, cardiac index $\left(1 / \mathrm{min} . / \mathrm{m}^{2}\right) ; \mathrm{NA}$, not available. 
cardiac index (CI) $2.2 \mathrm{l} / \mathrm{min} . / \mathrm{m}^{2}$. In addition to dopamine, dobutamine, and furosemide, nitroglycerin $(0.5 \mu \mathrm{g} / \mathrm{kg} / \mathrm{min}$.) was given because tricuspid and mitral regurgitation were detected by echocardiography, but it was not effective. Therefore, pimobendan $(0.12 \mathrm{mg} / \mathrm{kg})$, a positive inotropic and vasodilating drug, and amrinone (3 to $5 \mu \mathrm{g} / \mathrm{kg} / \mathrm{min}$.), a phosphodiesterase inhibitor, were tried. These drugs improved her PCWP decreased from 27 to $21 \mathrm{mmHg}$. The catheter was removed on day +41 as her cardiac function was well-controlled without symptoms. For improving cardiac function, an angiotensin converting enzyme (ACE) inhibitor (captopril) and low-dose beta-blocking agent (carvedilol) were started. Cardiac function recovered gradually and on day +142 , LVEF was $53 \%$. Bone marrow has been in complete remission, and the myeloblastoma is absent on CT examination. She was able to return to student life for 1 year and 9 months following the BMT. The patient had a Karnofsky score (Karnofsky et al. 1949) of $90 \%$ and her quality of life was not compromised until October 1997 when she relapsed with myeloblastoma and died of pneumonia in February 1998.

Autopsy disclosed that the cardiac muscle cells were atrophic and degenerated. Diffuse interstitial fibrosis was also observed. These findings are compatible with drug-induced cardiomyopathy (von Herbay et al. 1988).

\section{Discussion}

High-dose chemotherapy with or without TBI followed by SCT is a highly effective treatment for various malignancies. However, a group of patients with decreased cardiac function due to previous treatment with cardiotoxic drugs, such as anthracycline derivatives (Bu'Lock et al. 1993; Vora et al. 1996; Sadzuka et al. 1997; Singal et al. 1997), usually are excluded from such therapy. However, several studies of allo-SCT and autologous (auto-) SCT in patients with decreased cardiac function or cardiomyopathy have been reported (Bearman et al. 1990; Heyderman et al. 1991; Kakavas et al. 1995; Broady et al. 1998; Nicolini et al. 2000; Skinner et al. 2004). Kakavas et al. (1995) reported six allo- and autoBMT patients whose initial LVEF measured by radionucleotide gated blood pool imaging was less than 50\%. Bearman et al. (1990) reported that patients with LVEF less than 50\% had similar survival compared with patients whose LVEF was greater than $50 \%$. Yet, there are several reasons to avoid SCT for these patients; cardiomyopathy after BMT has been reported (Braverman et al. 1991), radiation and high-dose chemotherapeutic agents for conditioning are harmful to cardiac function (Cazin et al. 1986; von Herbay et al. 1988; Pihkala et al. 1994; Lele et al. 1996; Eames et al. 1997), and more than $1.55 \mathrm{~g} / \mathrm{m}^{2} /$ day of $\mathrm{CY}$

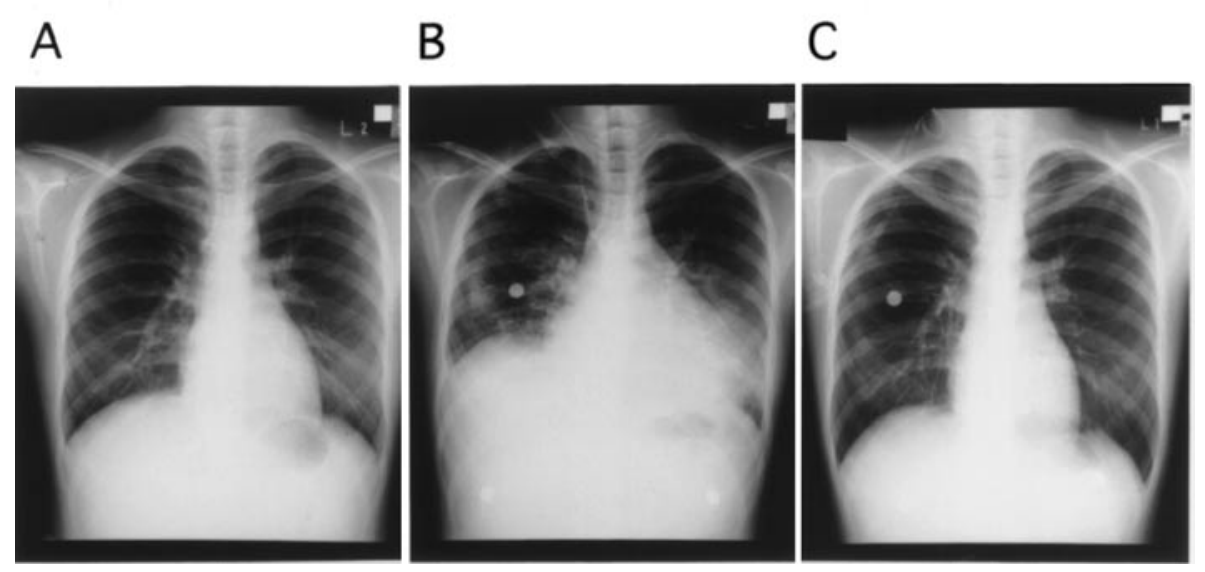

Fig. 2. Chest $\mathrm{X}$-ray of patient. A: Before BMT. B: Day +30 . Congestive heart failure increased. C: Day +64 . There was no heart failure signs. 
is cardiotoxic (Goldberg et al. 1986). Cardiac failure due to transplantation-related toxicity may be severe. Furthermore, extensive fluid administration is required to avoid hemorrhagic cystitis to CY. Nutrients and antibiotics are also given parenterally because nausea, vomiting, stomatitis, and diarrhea inhibit oral ingestion. Thus, volume overload can worsen cardiac function. Finally, circulatory management with a Swan-Ganz catheter may be difficult in clean room and may increase the possibility of severe infection during neutropenia.

Our case suggests that some patients with a very low LVEF may tolerate high-dose chemotherapies with TBI followed by SCT. However, consultation with cardiologists is important for such cases. The drugs and dosages chosen for pre-transplant conditioning should minimize cardiotoxicity. Several strategies can be used to reduce cardiotoxicity with conditioning. Divided infusions of CY may also reduce cardiotoxicity (Voelcker et al. 1984). Melphalan can be used instead of CY because of its low cardiac toxicity and less urinary injury (van Besien et al. 1995; Martino et al. 1995). In fact, we wanted to avoid CY administration, but we were unable to get melphalan, and the conditioning regimen was initially insufficient. So, we added CY administration. Recently, nonmyeloablative SCT has been performed with patients who were not candidates for conventional myeloablative therapy (Giralt et al. 1997; Slavin et al. 1998). This method might make it possible for patients with organ dysfunction, such as cardiomyopathy, to undergo SCT. The volume of intravenous infusion should be adjusted carefully to avoid volume overload. The stem cells should be concentrated by elimination of RBC and plasma. Hemodynamic management with a Swan-Ganz catheter is essential to detect early progression of congestive heart failure, in addition to monitoring heart rate, blood pressure, urinary volume, body weight, body temperature, and central venous pressure. Although SwanGanz catheter insertion is invasive and management is difficult, we were able to safely infuse the necessary volume of fluid during CY administration. However, long-term catheter use should be avoided because of the increased possibility of infection. Its management in clean rooms is difficult due to the confined space. In our case, the period of Swan-Ganz catheter detention was 1 week, and no complications were observed. Strict hemodynamic control with appropriate catecholamine, vasodilator, and diuretic therapy was critical. Finally, ACE inhibitors (Jensen et al. 1996) or long-term beta-blocking agents (Olsen et al. 1995) may be used to improve cardiac function after transplantation. These drugs caused the LVEF of this patient to improve from $20 \%$, the lowest value after BMT, to $53 \%$. Her cardiac dysfunction was reversible to some extent, but ACE inhibitors were effective in protecting cardiac function during SCT (Kakavas et al. 1995).

In conclusion, patients with low LVEF are not absolutely contraindicated from receiving SCT and can tolerate allo-SCT if strict hemodynamic management is done in close contact with cardiologists. In the future, such patients may benefit from receiving SCT, including nonmyeloablative SCT.

\section{Acknowledgments}

We thank Dr. Yuichi Akiyama (National Hospital Organization Kyoto Medical Center), for his useful advice, and Dr. Teruaki Akaogi (Kyoto Second Red Cross Hospital), who provided the patient's initial therapy and care.

\section{References}

Allen, A. (1992) The cardiotoxicity of chemotherapeutic drugs. Semin Oncol., 19, 529-542.

Ayash, L.J., Wright, J.E., Tretyakov, O., Gonin, R., Elias, A., Wheeler, C., Eder, J.P., Rosowsky, A., Antman, K. \& Frei, E.D. (1992) Cyclophosphamide pharmacokinetics: correlation with cardiac toxicity and tumor response. J. Clin. Oncol., 10, 995-1000.

Bearman, S.I., Petersen, F.B., Schor, R.A., Denney, J.D., Fisher, L.D., Appelbaum, F.R. \& Buckner, C.D. (1990) Radionuclide ejection fractions in the evaluation of patients being considered for bone marrow transplantation: risk for cardiac 
toxicity. Bone Marrow Transplant., 5, 173-177.

Bennett, J.M., Catovsky, D., Daniel, M., Flandrin, G., Galton, D.A.G., Gralnick, H.R. \& Sultan, C. (1976) Proposals for the classification of the acute leukaemias. Br. J. Haematol., 33, 451-458.

Braine, H.G., Sensenbrenner, L.L., Wright, S.K., Tutschka, P.J., Saral, R. \& Santos, G.W. (1982) Bone marrow transplantation with major ABO blood group incompatibility using erythrocyte depletion of marrow prior to infusion. Blood, 60, 420-425.

Braverman, A.C., Antin, J.H., Plappert, M.T., Cook, E.F. \& Lee, R.T. (1991) Cyclophosphamide cardiotoxicity in bone marrow transplantation: a prospective evaluation of new dosing regimens. J. Clin. Oncol., 9, 1215-1223.

Broady, R., Hawkins, T., Browett, P. \& Palmer, S. (1998) Successful allogeneic bone marrow transplant for chronic myeloid leukaemia despite previous interferon-induced cardiomyopathy. Bone Marrow Transplant., 21, 833-834.

Bu'Lock, F.A., Gabriel, H.M., Oakhill, A., Mott, M.G. \& Martin, R.P. (1993) Cardioprotection by ICRF187 against high dose anthracycline toxicity in children with malignant disease. $\mathrm{Br}$. Heart J., 70, 185-188.

Cazin, B., Gorin, N.C., Laporte, J.P., Gallet, B., Douay, L., Lopez, M., Najman, A. \& Duhamel, G. (1986) Cardiac complications after bone marrow transplantation. A report on a series of 63 consecutive transplantations. Cancer, 57, 2061-2069.

Eames, G.M., Crosson, J., Steinberger, J., Steinbuch, M., Krabill, K., Bass, J., Ramsay, N.K. \& Neglia, J.P. (1997) Cardiovascular function in children following bone marrow transplant: a cross-sectional study. Bone Marrow Transplant., 19, 61-66.

Forrester, J.S., Diamond, G.A. \& Swan, H.J.C. (1977) Correlative classification of clinical and hemodynamic function after acute myocardial infarction. Am. J. Cardiol., 39, 137-145.

Giralt, S., Estey, E., Albitar, M., van Besien, K., Rondon, G., Anderlini, P., O’Brien, S., Khouri, I., Gajewski, J., Mehra, R., Claxton, D., Andersson, B., Beran, M., Przepiorka, D., Koller, C., Kornblau, S., Korbling, M., Keating, M., Kantarjian, H. \& Champlin, R. (1997) Engraftment of allogeneic hematopoietic progenitor cells with purine analog-containing chemotherapy: harnessing graft-versus-leukemia without myeloablative therapy. Blood, $\mathbf{8 9}$, 4531-4536.

Goldberg, M.A., Antin, J.H., Guinan, E.C. \& Rappeport, J.M. (1986) Cyclophosphamide cardiotoxicity: an analysis of dosing as a risk factor. Blood, 68, 1114-1118.

Heyderman, R.S., Morgan, G., Levinsky, R.J. \& Strobel, S. (1991) Successful bone marrow transplantation and treatment of BCG infection in two patients with severe combined immunodeficiency. Eur. J. Pediatr., 150, 477-480.

Jensen, B.V., Nielsen, S.L. \& Skovsgaard, T. (1996) Treatment with angiotensin-converting-enzyme inhibitor for epirubicin-induced dilated cardiomyopathy. Lancet, 347, 297-299.

Kakavas, P.W., Ghalie, R., Parrillo, J.E., Kaizer, H. \& Barron, J.T. (1995) Angiotensin converting enzyme inhibitors in bone marrow transplant recipients with depressed left ventricular function. Bone Marrow Transplant., 15, 859-861.

Karnofsky, D.A. \& Burchenal, J.H. (1949) The clinical evaluation of chemotherapeutic agents in cancer. In: Evaluation of Chemotherapeutic Agents, edited by C.M. MacLeod, New York, Columbia University Press.

Lele, S.S., Durrant, S.T., Atherton, J.J., Moore, T.D., Thomson, H.L., Khafagi, F.A. \& Frenneaux, M.P. (1996) Demonstration of late cardiotoxicity following bone marrow transplantation by assessment of exercise diastolic filling characteristics. Bone Marrow Transplant., 17, 1113-1118.

Martino, R., Badell, I., Brunet, S., Sureda, A., Torras, A., Cubells, J. \& Domingo Albos, A. (1995) High-dose busulfan and melphalan before bone marrow transplantation for acute nonlymphoblastic leukemia. Bone Marrow Transplant., 16, 209-212.

Nicolini, B., Balduzzi, A., Tagliabue, A., Longoni, D., Uderzo, C. \& Galli, M.A. (2000) Mild pretransplant cardiomyopathy may not impair long-term quality of life after bone marrow transplantation. Bone Marrow Transplant., 25, 335-336.

Olsen, S.L., Gilbert, E.M., Renlund, D.G., Taylor, D.O., Yanowitz, F.D. \& Bristow, M.R. (1995) Carvedilol improves left ventricular function and symptoms in chronic heart failure: a doubleblind randomized study. J. Am. Coll. Cardiol., 25, 1225-1231.

Pihkala, J., Saarinen, U.M., Lundstrom, U., Salmo, M., Virkola, K., Virtanen, K., Siimes, M.A. \& 
Pesonen, E. (1994) Effects of bone marrow transplantation on myocardial function in children. Bone Marrow Transplant., 13, 149-155.

Sadzuka, Y., Sugiyama, T., Shimoi, K., Kinae, N. \& Hirota, S. (1997) Protective effect of flavonoids on doxorubicin-induced cardiotoxicity. Toxicol Lett., 92, 1-7.

Singal, P.K., Iliskovic, N., Li, T. \& Kumar, D. (1997) Adriamycin cardiomyopathy: pathophysiology and prevention. FASEB J., 11, 931-936.

Skinner, M., Sanchorawala, V., Seldin, D.C., Dember, L.M., Falk, R.H., Berk, J.L., Anderson, J.J., O’Hara, C., Finn, K.T., Libbey, C.A., Wiesman, J., Quillen, K., Swan, N. \& Wright, D.G. (2004) High-dose melphalan and autologous stem-cell transplantation in patients with AL amyloidosis: an 8-year study. Ann Intern. Med., 140, 85-93.

Slavin, S., Nagler, A., Naparstek, E., Kapelushnik, Y., Aker, M., Cividalli, G., Varadi, G., Kirschbaum, M., Ackerstein, A., Samuel, S., Amar, A., Brautbar, C., Ben-Tal, O., Eldor, A. \& Or, R. (1998) Nonmyeloablative stem cell transplantation and cell therapy as an alternative to con- ventional bone marrow transplantation with lethal cytoreduction for the treatment of malignant and nonmalignant hematologic diseases. Blood, 91, 756-763.

van Besien, K., Demuynck, H., Lemaistre, C.F., Bogaerts, M.A. \& Champlin, R. (1995) Highdose melphalan allows durable engraftment of allogeneic bone marrow. Bone Marrow Transplant., 15, 321-323.

Voelcker, G., Wagner, T., Wientzek, C. \& Hohorst, H.J. (1984) Pharmacokinetics of "activated" cyclophosphamide and therapeutic efficacies. Cancer, 54, 1179-1186.

von Herbay, A., Dorken, B., Mall, G. \& Korbling, M. (1988) Cardiac damage in autologous bone marrow transplant patients: an autopsy study. Cardiotoxic pretreatment as a major risk factor. Klin. Wochenschr., 66, 1175-1181.

Vora, J., Khaw, B.A., Narula, J. \& Boroujerdi, M. (1996) Protective effect of butylated hydroxyanisole on adriamycin-induced cardiotoxicity. J. Pharm. Pharmacol., 48, 940-944. 